\title{
LA CRISIS, UNA OPORTUNIDAD DE ACELERAR EL CAMBIO
}

\author{
Pedro Gamio Aita
}

Pontificia Universidad Católica del Perú

Resumen: En este artículo se examina la situación que atraviesa el país: la pandemia, la contaminación, el excesivo uso de energías contaminantes (mayormente basadas en hidrocarburos), así como la necesidad de un cambio gradual a energías más limpias que nos permitan hacer frente al problema de bioseguridad y el cambio climático. Asimismo, se plantea la necesidad de políticas públicas para promover el desarrollo sostenible del país.

Palabras clave: pandemia, hidrocarburos, energías renovables, contaminación ambiental, cambio climático, desarrollo sostenible, políticas públicas, medioambiente, matriz energética, energía eólica, geotermia, energía termosolar. 


\title{
The crisis, an opportunity to accelerate change
}

\begin{abstract}
In this article we examine the current situation of our country regarding the Pandemic and the excessive use of pollutant energy (mainly based in hydrocarbons), as well as the requirement of a gradual change to cleaner and renewable energy which will allow us to face the climate change. Also, the need of public politics to promote the sustainable and healthy development of our country.
\end{abstract}

Keywords: Pandemic, hydrocarbons, renewable energies, environmental pollution, climate change, sustainable development, public policies, environment, energy matrix, wind energy, geothermal energy, solar thermal energy.

\section{Pedro Gamio Aita}

Abogado con magister en Gestión de Políticas Públicas por la Universidad Carlos III de España y egresado de la Maestría de Ciencia Política de la Pontificia Universidad Católica del Perú. Postgrado en Gestión en ESAN, con especialización en Legislación Ambiental por la Universidad Politécnica de Madrid (España) y en Contratos de Energía por el Petroleum Institute of Texas. Actualmente es presidente del Panel Asesor de Monitoreo Independiente del Proyecto Camisea y consultor del GIZ. Asimismo, es integrante del Consejo Directivo de la Plataforma Latinoamericana de Energías Renovables (PLESE). Ha sido parte del equipo negociador del Perú en la COP 20 y coordinador de Energía, participante en la COP 21. Ha sido viceministro de Energía del Perú. Se ha desempeñado como consultor de la Fundación Adenauer, del Banco Mundial, del BID, PNUD, WWF, OEFA y CEPLAN en materia de energía y medio ambiente. Es profesor de la PUCP; miembro de la Asamblea del INTE-PUCP; miembro del Grupo de Investigación TINKUY: Energía, Territorio y Cambio Climático de la PUCP; miembro del Colectivo Acceso Básico a la Energía (GIZ, Soluciones Prácticas, PLEASE, IICA, INTEPUCP), y director de la Red de Energías Renovables.

Correo: gamio.f@pucp.edu 
De acuerdo a García et al. (2007), el mundo se encuentra desde hace algunos años en una situación de «emergencia planetaria». Dicho término se refiere a la capacidad de carga de nuestro planeta; es decir, la población de una especie que un hábitat determinado puede soportar indefinidamente sin dañar permanentemente el ecosistema del que son dependientes (Jansson et al.1994). La capacidad de carga humana, con un ajuste de la Tercera Ley de la Ecología Humana de Garret Hardin (Algara Sánchez de las Matas 2008), tiene que ser interpretada como la tasa máxima de consumo de recursos y descarga de residuos que se puede sostener indefinidamente sin desequilibrar progresivamente la integridad funcional y la productividad de los ecosistemas principales, sin importar dónde se encuentren estos últimos. Se está debilitando aceleradamente el escudo de protección que nos brinda la naturaleza y su biodiversidad ${ }^{1}$.

La emergencia en la Tierra fue evidente tras la presentación del informe de la ONU, «Revisión de las Perspectivas de Población Mundial» (ONU 2015). Ese mismo año fueron aprobados los Objetivos de Desarrollo Sostenible (ODS) de la mencionada organización global. El informe señalado concluye que el crecimiento demográfico exponencial, iniciado en 1800, generará graves consecuencias para los Estados que aún no han logrado reducir sus índices de pobreza y desigualdad, pues el crecimiento poblacional solo acentuaría las deficiencias existentes. Asimismo, la presión que representa sostener una población que parece no tener límites, acelera el proceso del calentamiento global, el cual deteriora - ahora de forma más visible- la capacidad de carga de nuestro planeta.

En atención a lo expuesto, el informe especial del Panel Intergubernamental Sobre el Cambio Climático (IPCC) del año 2018, alerta que el planeta se encamina a un calentamiento global cercano a $3^{\circ} \mathrm{C}$ por encima de los niveles preindustriales. Menciona que se espera que para el año 2030 el límite de 1.5C Cya se habrá alcanzado y continuará avanzando hacia temperaturas peligrosas, ocasionando olas de calor más frecuentes e intensas, tormentas más dañinas, aumento del nivel de los océanos por encima de las previsiones, frecuencia e intensidad

\footnotetext{
1 «La comunidad científica lleva años lanzando esta alerta: la pérdida de biodiversidad actúa como catalizador para la expansión de virus y enfermedades infecciosas. La razón es que la diversidad de animales y plantas funciona como un escudo protector. Muchas especies actúan como huéspedes de virus que ni siquiera conocemos aún. Si disminuimos esta diversidad y destruimos ecosistemas, facilitamos que dichos virus "salten" al ser humano. De hecho, se estima que el 75\% de las enfermedades nuevas emergentes que infectan a las personas proviene de animales» (Rodríguez 2020).
} 
de sequías; entre otros eventos que pueden tener un efecto multiplicador que le costará al planeta mucho, además de perder vidas humanas y ocasionar graves daños materiales (IPCC 2019).

Los impactos del calentamiento por encima de los $1.5^{\circ} \mathrm{C}$ afectarían desproporcionalmente a las poblaciones desfavorecidas y vulnerables a través de la inseguridad alimentaria, aumento de los precios de los alimentos, pérdida de ingresos, pérdida de oportunidades de subsistencia, efectos adversos para la salud, epidemias y desplazamientos de población. Mantener la temperatura global por debajo del límite inferior podría reducir la cantidad de personas expuestas a riesgos climáticos y vulnerables a la pobreza entre 62 a 457 millones, disminuyendo los riesgos de las personas pobres de experimentar inseguridad alimentaria y de agua, impactos adversos para la salud y pérdidas económicas (IPCC 2019).

El aumento en las concentraciones de gases de efecto invernadero tiene una estrecha relación con la alta demanda energética de la población. El suministro de energía mundial en la actualidad está basado en recursos que proceden en su mayoría de combustibles fósiles como el petróleo, carbón y gas natural, lo que conlleva a que se produzcan los siguientes problemas ambientales (Aguilar Peña et al. 1995).

- $\quad$ Agotamiento de los combustibles fósiles: Teniendo en cuenta que el ritmo de consumo es tal que en un año la humanidad consume lo que la naturaleza tarda un millón de años en producir.

- Lluvia ácida: La cual es originada por la combustión de combustibles fósiles que libera una importante cantidad de óxidos de azufre y nitrógeno que reaccionan con el radical $\mathrm{OH}$ en la atmósfera y precipitan en forma de ácidos (sulfúrico y nítrico), incrementando la acidificación de agua en general, la cual daña la vegetación y corroe estructuras.

- Efecto invernadero: Es la capacidad que tiene la atmósfera de retener calor. Es debido a la existencia de gases que son transparentes a la radiación solar y opacos a la radiación infrarroja emitida por la tierra, atrapando el calor entre la superficie de esta y el nivel medio de la atmósfera.

- Tensiones sociales: Los recursos energéticos, tanto fósiles como tecnológicos, están concentrados en unos pocos lugares de la Tierra. Por tanto, el acceso a ellos colisiona con problemas de transporte, equidad y distribución.

Es entonces donde se hace más evidente la correlación entre el agotamiento a mediano plazo de los recursos naturales y donde el uso eficiente de las reservas naturales existentes se torna imprescindible — cuando menos hasta que se pongan en marcha políticas agresivas de mitigación al continuo y desequilibrado crecimiento poblacional-. El sistema energético mundial tradicional es una fuente más del deterioro del ecosistema mundial, por ello no es posible desvincular la energía de los problemas socioambientales y de salud del mundo (Posso 2002). 
La temática de la energía es uno de los contenidos más trabajados en el ámbito de la educación formal, pero su tratamiento tradicional ha sido muy poco útil para cambiar el pensamiento y la conducta de las personas en relación con el modelo energético predominante en nuestra sociedad (García et al. 2007).

Con la pandemia se ha evidenciado la precariedad de nuestro sistema de salud y la urgencia de mejoras institucionales y de gestión. Hay pérdida de vidas humanas, pérdida de trabajos y crisis económica. Llama la atención que en plena pandemia, según la Encuesta de Apoyo y el diario El Comercio, publicada el 30 de abril del presente año, los peruanos señalan a la corrupción como el principal problema nacional, fruto de la indignación ciudadana por numerosas acciones cometidas por las autoridades, entre ellas el reparto irregular de canastas de alimentos realizado por algunos gobiernos locales. De acuerdo a estimaciones del Banco Mundial, se estima que el Perú pierde el 2\% del PBI al año por corrupción². La pandemia, la ubican en segundo lugar como problema nacional. Lo cierto es que debemos mejorar la gestión pública y tratar de evitar perder todo lo alcanzado, en situación de la economía y reducción de la pobreza. Debemos reconsiderar ir una cuarentena inteligente, y en las zonas donde sea necesario, sujetas a permanente monitoreo, así como aplicar una cuarentena georeferenciada, con pruebas moleculares, el riguroso uso de las mascarillas, el distanciamiento, el lavado periódico de las manos. Debemos reducir filtraciones, utilizar termómetros, masificar las pruebas moleculares, aislar los espacios de mayor contagio y ayudar a su recuperación. Debemos cautelar la salud y el bienestar básico de todos, al mismo tiempo proteger el sistema productivo y la economía. La crisis nos debe permitir, con una mejor gestión, acelerar la hoja de ruta, es decir, todo lo que no hicimos antes. Una gran enseñanza de esta pandemia es la importancia de una vida con higiene, lo que nos lleva a una cultura de la salud.

En el tema de transporte, el mayor uso de un combustible más barato y limpio, como el gas natural, que junto al uso de unidades nuevas y más económicas y eficientes puede mitigar la necesidad del uso de subsidios para la operación de un transporte racionalizado y que cumpla las normas de bioseguridad. En algunas actividades como aeropuertos, puertos, minería, y en el espacio de vehículos menores y mototaxis, se abre camino a la electromovilidad.

Debemos seguir con el operativo en mercados y centros de abastecimiento de alimentos - los mercados itinerantes ayudan mucho-, y se requiere de planes de emergencia para reubicar y organizar a tantos vendedores ambulantes, con control sanitario estricto. Hacer guías más simples y didácticas para el sector de Pymes. También el desarrollo de biohuertos urbanos ayuda a la seguridad alimentaria, de la mano con la implementación del plan nacional de biodigestores, para tener abonos y fertilizantes orgánicos. Debemos reducir la presencia en el mercado de agroquímicos tóxicos y de mala calidad, pues esto atenta contra la seguridad alimentaria.

\footnotetext{
2 Según declaraciones de Susana Silva, Coordinadora de la Comisión de Alto Nivel Anticorrupción (en Canal N, fecha 2 de octubre de 2014).
} 
Según un estudio de la Asociación «Escucha al Perú» ${ }^{3}$, el $70 \%$ de la población ha visto afectada su economía y alimentación, el $50 \%$ ha perdido su empleo, el $30 \%$ de universitarios han dejado de estudiar y 4 de cada 10 personas necesitadas no acceden a los programas estatales. Unir esfuerzos articulados con el sector privado y la academia no es solo tarea del Gobierno. Los bonos de ayuda no pueden sostenerse por mucho tiempo, hay que hacer programas de inserción y reactivación a la economía de las Pymes, ya no solo de las grandes empresas. La mitad de las pequeñas empresas ha sido afectada severamente. Todos debemos comprender que vamos hacia un nuevo orden sanitario. Somos un país en guerra.

La presión tributaria tiene que recuperarse gradualmente y llegar al $20 \%$, como nunca antes, para poder invertir el doble de lo que se invierte en educación y salud. En ciencia y tecnología tenemos que invertir cinco veces más. Pasar al gobierno electrónico, asegurar transparencia y eficacia en el acceso a la energía, el agua potable y la conectividad. Tratar los residuos sólidos y las aguas servidas. Economía circular.

En el sector energía la demanda eléctrica cae junto con el crecimiento económico. La falta de pago de los recibos por el servicio eléctrico afecta la cadena de pagos y amenaza la operatividad del sector eléctrico. La sobreoferta de generación se mantendría, cuanto menos, hasta 2024 (Diario Digital de Minería 2020). Hubo una fuerte disminución de la demanda eléctrica. Principalmente por la disminución de la demanda de las grandes cargas mineras, industriales y clientes comerciales (Serebrisky et al. 2020). El despacho de la generación eléctrica ha sido principalmente renovable, en base a la hidroelectricidad, complementariamente solar, eólica y biomasa, con limitada participación de la generación térmica a gas natural en las horas punta.

Se mantiene la distorsión de precios entre clientes libres y clientes regulados, estos últimos pagan el doble por la generación. La disminución de la demanda ha generado algunos problemas de sobretensión en las redes de distribución, con lo cual se han incrementado las fallas en algunas zonas. Las empresas señalan que, si bien en marzo se ha recaudado aproximadamente el 50\%, en abril, mayo y junio esto habría disminuido al $30 \%$, ya sea por falta de pago o por el fraccionamiento de los pagos, que ahora ha sido ampliado a un mayor universo de consumidores regulados favorecidos. Ahora el fraccionamiento beneficia a las personas que pagan mensualmente hasta un monto estimado de 150 soles. Esto obliga a las empresas distribuidoras a financiar una deuda mayor. No obstante, los intereses compensatorios por el fraccionamiento de los consumidores serán asumidos por el FISE. El tema es que esto se haga pronto. Si no, se afecta a las distribuidoras. Respecto de la falta de pago de los mayores consumidores, por ahora corresponde a cada empresa distribuidora entablar comunicación con cada uno de ellos para que puedan acordar los pagos o proceder al corte.

3 La encuesta, realizada con la agencia Pacific Edelman Affiliate, fue aplicada a hombres y mujeres mayores de 18 años pertenecientes a 437 hogares en los 41 distritos de Lima Metropolitana y Callao. 
En los hogares y el transporte, el GLP ha sido por mucho tiempo un competidor desleal del gas natural, por los subsidios y el contrabando interno entre el precio del GLP envasado y el GLP a granel. Hoy somos importadores netos de GLP4.

Debemos aumentar la productividad y competitividad de las Pyme, obtener precios más competitivos de energía, utilizar combustibles más limpios y acelerar así el proceso de reactivación de la economía. Esto se puede lograr promoviendo las energías renovables y la eficiencia energética. Una de las medidas de reactivación económica es la introducción de medidas de eficiencia energética y la generación distribuida para las Mypes, y de esta manera disminuir gradualmente sus costos de electricidad y disminuir la emisión de GEI ${ }^{5}$. La eficiencia energética en las PYMES puede ayudar mucho con programas y ofertas de crédito blando y asistencia técnica para elevar productividad y reducir costos en tantos pequeños emprendimientos. Acompañar la bioseguridad, mejorando la competitividad de las pequeñas empresas para que tengan capacidad de respuesta. Se lograría ahorro de costos por optimización en el uso de recursos, generar mayor confianza de los clientes y consumidores. Rentabilidad y competitividad en sus mercados. Fortalecimiento de los procesos y cadenas productivas. Ampliar la infraestructura y mejorar la tecnología.

La generación distribuida o descentralizada es parte de en una ciudad sostenible e inteligente. Consiste en la generación de energía eléctrica solar mediante muchas pequeñas fuentes de generación que se instalan cerca de los puntos de consumo. La generación distribuida se basa en la cooperación entre esta microgeneración, el distribuidor y la generación de las centrales convencionales. Esta distribución hace que la generación sea más equilibrada, y que la ciudad inteligente o «Smart City» no dependa tanto de las grandes centrales. Además, la microgeneración implica el uso de las energías renovables, lo que contribuye a reducir costos y contaminación, reducir las emisiones de $\mathrm{CO}^{2}$. Debemos desarrollar pilotos en el sistema interconectado y en sistemas aislados.

\section{Conclusiones}

En resumen, tenemos que mejorar la gestión del Estado, en todos los niveles. Manejo integrado y electrónico de los servicios de salud y educación. En energía, otorgar incentivos a las empresas concesionarias de distribución eléctrica para el desarrollo de un programa de distribución de lámparas LED, más eficientes. Contar con el apoyo del FISE y el compromiso de los gobiernos locales involucrados. Implementar proyectos piloto que permitan generar información y testimonios de las mejores prácticas. Es importante contar con los recursos necesarios para

\footnotetext{
4 De acuerdo al Informe del Sector Gas en Perú 2019, IV Edición.

5 El viernes 23 de agosto de 2019, el presidente Martín Vizcarra inauguró el Centro de Innovación Productiva y Transferencia Tecnológica Agroindustrial (CITE) en Oxapampa, y declaró: «Las PYME representan el 95\% de empresas en el Perú y ofrecen trabajo a más de 8 millones de ciudadanos».
} 
la inversión en estas nuevas oportunidades, operación y mantenimiento de las medidas. Promocionar y socializar las medidas a nivel nacional. Hay cuatro componentes fundamentales: i) eficiencia energética y generación distribuida, orientada a reducir el consumo energético por parte de productores y usuarios finales. ii) Energías renovables, con las cuales se busca incrementar la participación de fuentes renovables en la matriz energética del sistema interconectado, para reducir costos de la energía y descentralizar la infraestructura. iii) Transporte sostenible con gas natural y electromovilidad, enfocado en el uso de fuentes energéticas que generen menos emisiones de GEI, en reemplazo del diésel. Se busca incrementar el uso de vehículos eléctricos, híbridos o con combustibles fósiles más eficientes y menos contaminantes en la flota vehicular, como es el gas natural. Esto mitiga la necesidad de subsidios al transporte. iv) Promover construcciones bioclimáticas, para acompañar el ordenamiento territorial hacia ciudades más verdes y sustentables. Ciudades donde se trabaje en la seguridad alimentaria, seguridad hídrica y seguridad energética. Lo mencionado, el desarrollo de biohuertos urbanos, de la mano con la implementación del plan nacional de biodigestores, para tener abono y fertilizante orgánico, mejora la calidad de los alimentos. Cuidar y reusar el agua, que se conserva por el cuidado de todos, con el buen trato de las nacientes, los bofedales y a todo el recorrido del río, con la reforestación de las riveras y evitar arrojar desechos diversos. Las crisis son una brillante oportunidad para acelerar los cambios. Hay que tomar decisiones.

En los hogares hay que defender la economía familiar con servicios cada vez más eficientes, más limpios y económicos. El gas natural y las energías renovables ayudan mucho al presupuesto familiar. Las familias que usan gas natural o termas solares ahorran bastante. Sobre la posibilidad de lograr mejoras importantes del transporte público, se debe cumplir las normas de bioseguridad, además pensar en unidades nuevas y chatarrear la vieja flota a diésel, optando por buses más eficientes y económicos y al mismo tiempo menos contaminantes. Esto significa modernizar la flota y reducir el subsidio al transporte.

En transporte, el gas significa no menos de un tercio frente al diésel, 46\% con relación al uso de balones de GLP en los hogares y $70 \%$ respecto al consumo de electricidad. Más de 1 millón de hogares ya están conectados al gas natural, llevando los beneficios del gas natural a 5 millones de peruanos. Pero el índice de penetración es de solo 20\%, mientras que Colombia está en $72 \%$ y Bolivia en $43 \%$. No estamos aprovechando la ventaja de contar con este recurso como podemos. La combinación entre gas natural y energías renovables se conoce como transición energética, y nos permite tener mejor capacidad de respuesta y de resiliencia en tiempos de pandemia. Pero no debemos olvidar el norte, tal y como lo indica la ONU: «cualquier impacto ambiental positivo que surja de esta aborrecible pandemia debe ser un cambio en nuestros hábitos de producción y consumo hacia un ambiente más limpio y ecológico» (Noticias ONU 2020). 


\section{Referencias}

Aguilar Peña, J. D., Gómez Segura, A. y de Torres Catalán, R. (1995). Riesgos del sistema energético actual. En Conferencia Inaugural del Curso 1995-96 en el Instituto de Estudios Giennenses. Universidad de Jaén. http://www.ujaen. es/investiga/solar/07cursosolar/home_main_frame/08_lecciones/01_ leccion/www/riesgos_del_sistema_energetico_a.htm

Algara Sánchez de las Matas, M. (2008). Las leyes de la ecología. https://webapps. unibague.edu.co/leyesecologia.pdf

Diario digital de Minería, Energía y Construcción (13 de abril, 2020). Informe de situación del sector energía, a cargo de los principales actores.

García, J. E., Rodriguez, F., Solís. M. C. y Ballenilla, F. (2007). Investigando el problema del uso de la energía. Investigación en la escuela Sevilla, (62): 29-45. https://idus.us.es/bitstream/handle/11441/60875/R63_3. pdf;jsessionid=884B8C092B695855EC3A45ADABB88FF2

IPCC (2019). Informe Especial. Calentamiento Global de $1.5^{\circ} \mathrm{C}$. Informe especial del IPCC sobre los impactos del calentamiento global de $1,5^{\circ}$. Grupo Intergubernamental de Expertos sobre el Cambio Climático. https://www. ipcc.ch/site/assets/uploads/sites/2/2019/09/IPCC-Special-Report-1.5SPM_es.pdf

Jansson, A. (Editor), Hammer, M., Folke, C., Costanza, R. (Eds.) (1994). Investing in Natural Capital: The Ecological Economics Approach To Sustainability (International Society for Ecological Economics). Island Press.

Noticias ONU ( 7 de abril del 2020). La pandemia de coronavirus es una oportunidad para construir una economía que preserve la salud del planeta. NoticiasONU. https://news.un.org/es/story/2020/04/1472482

ONU (2015). World Population Prospects: The 2015 Revision, Key Findings and Advance Tables. Working Paper No. ESA/P/WP.241. https://population. un.org/wpp/Publications/Files/Key_Findings_WPP_2015.pdf

Posso, F. (2002). Energía y ambiente: pasado, presente y futuro. Geoenseñanza, 7(1-2): 54-73.

Rodríguez, B. (2020). COVID-19 y cambio climático: cinco lecciones que nos deja la pandemia. En Blog virtual de Ayuda en Acción. https://ayudaenaccion.org/ ong/blog/sostenibilidad/covid-19-cambio-climatico/

Serebrisky, T.; Brichetti, J.P.; Rivas Amiasorho, M.E.; Sanin Vazquez, M.E (2020). El impacto del COVID-19 en la demanda de servicios. Blog BID, Mejorando vidas. $\quad$ https://blogs.iadb.org/agua/es/servicios-de-infraestructuraasequibles-para-todos-en-tiempos-de-coronavirus-y-mas-alla/ 